\title{
Development of associated vaccine against Piv-3, Ibr, Bvd and chlamidiosis of cattle
}

\author{
Vitaliy V. Evstifeev ${ }^{1}$, Ilgizar R. Akbashev ${ }^{1}$, Sergey I. Yakovlev ${ }^{1}$, Maxim I. Klyatskiy ${ }^{1}$, and Ilsur G. Galimzyanov ${ }^{2}$ * \\ ${ }^{1}$ Federal Center for Toxicological, Radiation and Biological Safety - All Russian Research Veterinary Institute, 420075 Kazan, Russia \\ ${ }^{2}$ Kazan State Academy of Veterinary Medicine named after N. E. Bauman, 420029 Kazan, Russia
}

\begin{abstract}
As a result of clinical and epizootological examination of dysfunctional farms with respiratory and intestinal infections, the main agents of pneumoenteritis of calves and based on this we developed and associated inactivated vaccine against PIV-3, IBR, BVD and chlamidiosis were identified. The results of laboratory and production tests showed that it has high antigenic activity and immunogenic properties for laboratory animals, and its use in dysfunctional farms reduces the incidence of young animals, increases their birth rate and safety which has a positive effect on the efficiency of cattle breeding.
\end{abstract}

\section{Introduction}

In the conditions of modern livestock breeding, the main reason for the respiratory diseases of livestock is a decrease of its resistance [1].

Reoviruses of young cattle remain one of the most difficult problems of the infectious pathology of animals. In most cases, these diseases have a polyetiological structure, they manifest by severe pathological processes and cause significant economic damage to livestock in many regions of the Russian Federation. The incidence rate can reach from 80 to $100 \%$, the mortality rate up to $40 \%[2,3]$. At the same time viral-bacterial mixed pathologies in which parainfluenza-3, infectious bovine rhinotracheitis, bovine viral diarrhea and chlamidiosis play a major part have become the most serious problem of livestock farms [2, 4].

The causative agents of respiratory and intestinal diseases in cattle inhibit the cellular and humoral parts of the immune system, especially if they are in associations. As a rule, in order to save the stock of young animals, drugs that stimulate immunoreactivity and natural resistance of the organism are used [1].

Considering the above, it is obvious that the specific prevention of these mixed infections should be carried out using the associated vaccines.

The use of inactivated vaccines plays a very important role in the prevention of infectious diseases the pathogens of which can persist in animals' organisms for a long time against an immune background [2-5].

Considering this, in FSBSI «FCTRB-VNIVI» the «Associated vaccine against parainfluenza-3, infectious bovine rhinotracheitis and chlamidiosis of livestock, inactivated emulsive» was developed which showed high efficiency in dysfunctional livestock farms. However, due to the import of cattle into the Russian Federation the amount of the animals seropositive to BVD has increased [2].

Considering this, we faced the necessity to improve this vaccine by expanding its antigenic spectrum adding the BVD into it.

\section{Materials and methods}

The authors carried out clinical and epizootological examination of dysfunctional farms, where diseases of calves caused by reoviruses were recorded, in accordance with the "Methodological guidelines for comprehensive clinical examination of cattle" and "Recommendations on the methodology of epizootological research" [6, 7].

The diagnosis in the surveyed farms was established on the basis of epizootological, clinical, pathological, bacteriological, virological and serological studies.

During our work we used the following strains of viruses and chlamydia: vaccine strain «TK-A (VIEV)-B2» of IBR; reference strain «PTK-45/86» of PIV-3; vaccine strain «VK-1(VIEV)» of BVD; production strain «250» agent of chlamydial abortion of cattle.

For the production of biomass in order to produce specific antigens we used passaged culture of cow embryo kidney cells (MDBK line), passaged culture cow embryo lungs cells (LEK line), continuous line of Syrian hamster kidney cells (VNK-21/13), 6-11 days old chick embryos. As adjuvants we used an oil-lanolin adjuvant, aluminum hydroxide and two variants of commercial adjuvants: ISA-50 and ISA-61.

The sterility of the experimental series of vaccine against cattle chlamidiosis, inactivated emulsion, was determined according to GOST R 28085 by inoculating meat-peptone agar (MPA), meat-peptone broth (MPB), Sabouraud agar and Kitt-Tarozzi medium (MPPB) on bacterial culture media.

Corresponding author: ilsour@ rambler.ru 
The safety was determined on white laboratory mice with a live weight of $16-20 \mathrm{~g}$ by intraperitoneal administration of the vaccine at a dose of $0.25-0.3 \mathrm{~cm}^{3}$ and further observation for 10 days. We used 20 white mice which were divided into two equal groups: experimental and control.

As laboratory animals we used rabbits weighing $2.5-330 \mathrm{~kg}$, white mice weighing 16-20 g. Besides, we conducted the production tests on the black-and-white cattle of different age.

Seroimmunological monitoring was based on the detection of abtibodies to PIV-3, IBR, BVD and chlamydia.

Antibodies to PIV-3 were detected in the reaction of inhibition of hemagglutination using the set of FSI «Kurskaya biofabrika - firm «BIOK».

Antibodies to IBR were detected with the help of the method of enzyme immunoassay (EIA) using «Enzyme immunoassay test-system to detect antibodies to IBR (EIA-ANTI-IBR), produced in FSBSI «FCTRBVNIVI», and also «IBR-SEROTEST» (manufacturer «VETbiohim» Ltd, Moscow).

Antibodies to BVD were detected with the help of EIA and using «Enzyme immunoassay test-system to detect antibodies to BVD (EIA-ANTI- EIA-ANTI-)», produced in FSBSI «FCTRB-VNIVI».

The level of chlamydia antibodies was detected in compliment binding reaction using «A set of antigens and serums for serological diagnosis of chlamydia of farm animals» (ROSS RU.ФB01.H00022) produced by FSBSI «FCTRB-VNIVI» [8].

The vaccination dose was determined on 20 rabbits with a live weight of $2.5-3.0 \mathrm{~kg}$. The animals were distributed into 4 groups ( 3 experimental and 1 control group) of 5 animals in each. The animals of the experimental groups were vaccinated 2 times with an interval of 15 days with the "Associated vaccine against PIV-3, IBR, BVD and chlamydia, inactivated emulsion" based on OLA adjuvant in doses of $0.5 \mathrm{~cm}^{3}, 1.0 \mathrm{~cm}^{3}$ and $2.0 \mathrm{~cm}^{3}$, respectively. The dynamics of the accumulation of antibodies in the blood serum of rabbits was determined before vaccination and 15, 30, and 60 days after administration of the preparation in reaction of inhibition of hemagglutination to PIV-3 virus, to IBR and BVD viruses in the method of enzyme immunoassay and in compliment binding reaction to chlamydia.

To confirm the viral and chlamydial etiology of the manifestation of clinical signs in experimentally infected calves, virological and bacteriological studies were performed. For the re-isolation of viruses and chlamydia in experimentally infected animals we systematically took their nasal swabs. Also, upon completion of observations, we carried out pathological studies of animals from the experimental and control groups. The resulting samples were used to infect cell cultures and chicken embryos.

Damage from death, forced slaughter, alienation and destruction of animals for each respective age group was measured according to «Methods for determining the economic efficiency of veterinary procedures», approved by the chief of the Veterinary Department of the
Ministry of Agriculture of Russian Federation V.M. Avilov on February, 211997 [9].

\section{Research results}

Initially we produced 4 variants of the associated inactivated vaccine against PIV-3, IBR, BVD and chlamidiosis: in the first variant we used polyethylsiloxane-3+lanolin (OLA) as adjuvant; in the second variant - ISA-50; in the third variant - ISA-61 and in the fourth variant - aluminum hydroxide $\left(\mathrm{Al}(\mathrm{OH})_{3}\right)_{\text {. }}$

When determining the sterility of the tested vaccines for a certain period of time, we did not detect any growth of bacterial and fungal microflora on nutrient media.

The vaccine safety test showed that after injection of the vaccine, deterioration in condition of white mice was not observed. The survival rate of mice, both in the experimental and in the control groups was $100 \%$, which indicated the safety of the tested vaccine.

Evaluation of the antigenic activity of 4 variants of the experimental vaccine series against PIV-3, IBR, BVD and chlamidiosis were conducted on 20 rabbits weighing $2.5-3.0 \mathrm{~kg}$, divided into 5 main groups, 4 animals in each. In all groups of animals, vaccinated with various variants of the associated vaccine, at different periods of the study we detected specific antibodies to PIV-3, IBR, BVD and chlamidiosis antigen which allowed concluding that all 4 variants of the vaccine are highly antigenic.

Table 1. Average titers of specific antibodies in rabbits

\begin{tabular}{|c|c|c|c|c|}
\hline \multirow[b]{2}{*}{ Adjuvants } & \multirow[b]{2}{*}{ Agents } & \multicolumn{3}{|c|}{ Days after vaccination } \\
\hline & & $\begin{array}{c}14 \\
\text { days }\end{array}$ & $\begin{array}{c}30 \\
\text { days }\end{array}$ & $\begin{array}{c}60 \\
\text { days }\end{array}$ \\
\hline \multirow{4}{*}{ OLA } & PIV-3 (RIH) & $1: 140$ & $11: 120$ & $1: 800$ \\
\hline & IBR (EIA) & $1: 500$ & $1: 650$ & $1: 2350$ \\
\hline & BVD (EIA) & $1: 650$ & $1: 1200$ & $1: 3750$ \\
\hline & $\begin{array}{l}\text { Chlamidiosis } \\
\text { (CBR) }\end{array}$ & $1: 15$ & $1: 20$ & $1: 20$ \\
\hline \multirow{4}{*}{ ISA-50 } & PIV-3 (RIH) & $1: 400$ & $1: 520$ & $1: 260$ \\
\hline & IBR (EIA) & $1: 350$ & $1: 600$ & $1: 900$ \\
\hline & BVD (EIA) & $1: 200$ & $1: 800$ & $1: 2050$ \\
\hline & $\begin{array}{l}\text { Chlamidiosis } \\
\text { (CBR) }\end{array}$ & $1: 5$ & $1: 12,5$ & $1: 17,5$ \\
\hline \multirow{4}{*}{ ISA-61 } & PIV-3 (RIH) & $1: 205$ & $1: 150$ & $1: 160$ \\
\hline & IBR (EIA) & $1: 350$ & $1: 325$ & $1: 800$ \\
\hline & BVD (EIA) & $1: 300$ & $1: 700$ & $1: 1900$ \\
\hline & $\begin{array}{c}\text { Chlamidiosis } \\
(\mathrm{CBR})\end{array}$ & $1: 3,75$ & $1: 5$ & $1: 17,5$ \\
\hline \multirow{4}{*}{$\mathrm{Al}(\mathrm{OH})_{3}$} & PIV-3 (RIH) & $1: 285$ & $1: 105$ & $1: 280$ \\
\hline & IBR (EIA) & $1: 145$ & $1: 250$ & $1: 400$ \\
\hline & BVD (EIA) & $1: 500$ & $1: 850$ & $1: 650$ \\
\hline & $\begin{array}{c}\text { Chlamidiosis } \\
(\mathrm{CBR})\end{array}$ & $1: 7,5$ & $1: 15$ & $1: 15$ \\
\hline
\end{tabular}

According to the results of the research, we observed a significant increase in specific vaccine antibodies based on OLA where the average titer was 1:2350. The other variants of the vaccine led to an insignificant increase of antibodies to a given antigen. The average 
titers were 1:900, 1:800, 1:400 respectively with ISA-50, ISA-61 and $\mathrm{Al}(\mathrm{OH})_{3}$ vaccines (Table 1).

To determine the vaccination dose, we formed 3 experimental groups and 1 control group of rabbits of 5 animals in each.

The animals of the experimental groups were vaccinated twice with an interval of 15 days, intramuscularly in the following doses: $1-0.5 \mathrm{~cm}^{3}, 2$ $1.0 \mathrm{~cm}^{3}$ and $3-2.0 \mathrm{~cm}^{3}$. The unvaccinated 4 th group of rabbits was a control group. We took blood for serological tests before vaccination, after 15 days (revaccination), 1 and 3 months from the start of the experiment. Antibodies in blood serum to PIV-3 viruses were determined in reaction of inhibition of hemagglutination, to IBR in the method of enzyme immunoassay, to BVD in the method of enzyme immunoassay, and to chlamydia in compliment binding reaction. The research results are presented in table 2 .

Table 2. The level of specific antibodies in the blood of rabbits at 15,30 and 60 days after vaccination

\begin{tabular}{|c|l|c|c|c|}
\hline Group & \multicolumn{1}{|c|}{ Agents } & \multicolumn{3}{|c|}{ Average antibody titers } \\
\hline \multirow{4}{*}{1} & & $\begin{array}{c}15 \\
\text { days }\end{array}$ & $\begin{array}{c}30 \\
\text { days }\end{array}$ & $\begin{array}{c}60 \\
\text { days }\end{array}$ \\
\hline \multirow{7}{*}{2} & PIV-3 & $1: 6$ & $1: 15$ & $1: 120$ \\
\cline { 2 - 5 } & IBR & $1: 100$ & $1: 100$ & $1: 400$ \\
\cline { 2 - 5 } & BVD & - & $1: 200$ & $1: 400$ \\
\cline { 2 - 5 } & Chlamidiosis & $1: 5$ & $1: 10$ & $1: 15$ \\
\hline \multirow{4}{*}{3} & PIV-3 & $1: 10$ & $1: 120$ & $1: 720$ \\
\cline { 2 - 5 } & IBR & $1: 300$ & $1: 550$ & $1: 1800$ \\
\cline { 2 - 5 } & BVD & $1: 125$ & $1: 950$ & $1: 2950$ \\
\cline { 2 - 5 } & Chlamidiosis & $1: 6$ & $1: 18$ & $1: 50$ \\
\hline \multirow{4}{*}{3} & PIV-3 & $1: 86$ & $1: 160$ & $1: 800$ \\
\cline { 2 - 5 } & IBR & $1: 475$ & $1: 650$ & $1: 2350$ \\
\cline { 2 - 5 } & BVD & $1: 875$ & $1: 1200$ & $1: 3750$ \\
\cline { 2 - 5 } & Chlamidiosis & $1: 6$ & $1: 20$ & $1: 60$ \\
\hline \multirow{4}{*}{4} & PIV-3 & - & - & - \\
\cline { 2 - 5 } & IBR & - & - & - \\
\cline { 2 - 5 } & BVD & - & - & - \\
\cline { 2 - 5 } & Chlamidiosis & - & - & - \\
\hline
\end{tabular}

The results of the research show that the administration of a vaccine in various doses stimulates the production of antibodies in the blood of rabbits in all 3 experimental groups. We found out that the vaccine dose of $0.5 \mathrm{~cm}^{3}$ induced a relatively low level of specific antibodies. High antibody titers were detected in the groups vaccinated at doses of 1.0 and $2.0 \mathrm{~cm}^{3}$. On the 60th day after immunization, the titers of postvaccination antibodies in animals of these groups to all antigens were approximately at the same level and amounted to the PIV-3 virus 1: 720 - 1: 800 , to the IBR virus $1: 1800-1: 2350$, to the BVD virus $1: 2950-1$ : 3750 and to chlamydiosis 1: 50-1: 60, respectively.

Based on the results of the studies, the OLA vaccine was chosen as the best option and we determined the vaccination dose of $1.0 \mathrm{~cm}^{3}$ which was used in an acute experiment on 5 calves of 10 days of age.

The animals were divided into 2 groups: 3 animals were in an experimental group and 2 animals were in a control group. The experimental group was vaccinated with «Associated vaccine against PIV-3, IBR, BVD and chlamidiosis, inactivated emulsive» twice with an interval of 14 in a dose of $1.0 \mathrm{~cm}^{3}$. The control group calves were not vaccinated.

30 days after revaccination, the animals of the experimental and control groups were infected with epizootic strains of viruses and chlamydia: «KA-9»epizootic strain of cattle herpesvirus of type-1 with an infectious titer $6.25 \mathrm{lg} \mathrm{TCD}{ }_{50} / \mathrm{ml}$; «ABA-13»-BVD viral isolate with an infectious titer $6.0 \mathrm{lg} \mathrm{TCD}_{50} / \mathrm{ml}$; «TM-50» - PIV-3 viral isolate with an infectious titer $5.5 \mathrm{lg}$ $\mathrm{TCD}_{50} / \mathrm{ml}$; «M3» - cattle chlamidiosis agent with an infectious titer $10^{-6.5} \mathrm{LD}_{50} / 0.3 \mathrm{ml}$.

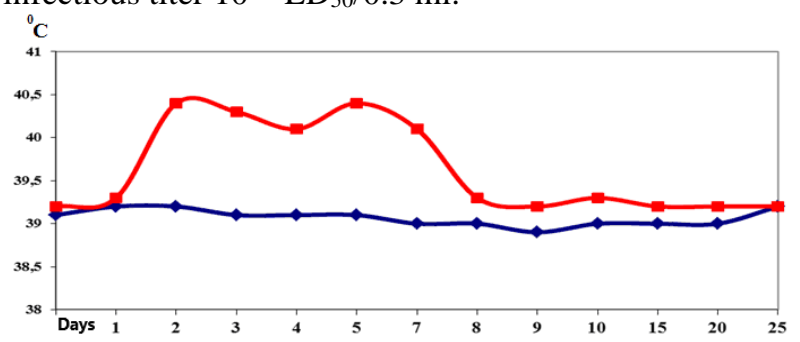

Fig. 1. Experimental calves average temperature curve (blue not vaccinated, red - vaccinated)

After experimental infection, the calves of the experimental group did not show a temperature rise, while the control group animals had hyperthermia which showed an increase in rectal temperature up to $39.7-40.6{ }^{\circ} \mathrm{C}$ on the 2 nd day after the introduction of virulent strains of viruses and Chlamydia, the results of which are presented in diagram 1 .

They remained in this condition during 7 days after the moment of infection. At the same time we observed clear signs of respiratory and intestinal pathology in all control group animals characterized by refusal from food, rapid breathing, dry cough, mucous-serous outflows from eyes and noses, erosion on the nose mirror and diarrhea. The vaccinated animals had no clinical signs of infection during the whole experimental period.

The analysis of the results of seroimmunological studies conducted during the experiment revealed that before the vaccination all calves had no antibodies to PIV-3, IBR, BVD and chlamidiosis. Double vaccination caused increase of the specific antibodies titers 30 days after the revaccination which were registered within 1:1280-1:2560 to PIV-3 in the reaction of inhibition of hemagglutination, 1:1600-1:3200 to herpesvirus of type 1 in IEA, 1:1600-1:12800 to viral diarrhea in IEA and 1:10-1:80 to chlamydia antigen in compliment binding reaction (Table 3 ).

During the study of blood serum of experimental calves on the 7th and 25th days after infection, a nonsignificant decrease in titers of post-vaccination antibodies was detected.

In control animals both at the initial blood sampling and before infection, specific antibodies to the desired antigens were not detected. On the 7th day after infection a slight increase in titers to all injected infectious agents was observed. And only on the 25th day post-infection specific antibodies were detected in the blood serum 
samples of control animals in diagnostic titers: to PIV-3 - 1:40-1:80; to IBR - 1:200-1:400; to BVD $1: 200-1: 400$ and to chlamydial antigen $-1: 10-1: 20$.

The results of an acute experiment showed that the tested vaccine has high antigenic and immunogenic properties.

Virological and bacteriological studies of clinical materials (nasal and ocular swabs) taken from calves from the experimental group 4, 6, 8, 10, 15 and 25 days after infection, were negative. We found that all epizootic viral and chlamydial agents used to infect control animals were taken from nasal and ophthalmic samples during the clinical manifestation of respiratory and intestinal pathology. Thus, on the $4-8^{\text {th }}$ day after the infection all the original virus strains and the strain of the cattle chlamydiosis agent were isolated from two control animals: from cell culture and chicken embryos.

Table 3. Reciprocal value of the titers of antibodies to viral and chlamydial antigens at different periods of time

\begin{tabular}{|c|c|c|c|c|c|}
\hline \multirow[b]{2}{*}{$\begin{array}{c}\mathrm{Gr} \\
\mathrm{ou} \\
\mathrm{p}\end{array}$} & \multirow{2}{*}{$\begin{array}{c}№ \\
\text { of } \\
\text { ani- } \\
\text { mal }\end{array}$} & \multirow[b]{2}{*}{ Agents } & \multicolumn{3}{|c|}{ Days of the experiments } \\
\hline & & & $\begin{array}{l}30 \text { days } \\
\text { before } \\
\text { infection }\end{array}$ & $\begin{array}{c}7 \text { days } \\
\text { after } \\
\text { infection }\end{array}$ & $\begin{array}{l}25 \text { days } \\
\text { after } \\
\text { infection }\end{array}$ \\
\hline \multirow{12}{*}{ 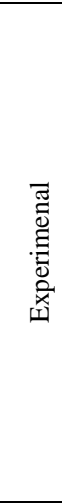 } & \multirow{4}{*}{1} & PIV-3 (RIH) & 1280 & 640 & 640 \\
\hline & & IBR (EIA) & 3200 & 1600 & 3200 \\
\hline & & BVD (EIA) & 3200 & 1600 & 3200 \\
\hline & & $\begin{array}{l}\text { Chlamidiosis } \\
\text { (CBR) }\end{array}$ & 80 & 40 & 40 \\
\hline & \multirow{4}{*}{2} & PIV-3 (RIH) & 1280 & 640 & 640 \\
\hline & & IBR (EIA) & 1600 & 800 & 1600 \\
\hline & & BVD (EIA) & 1600 & 1600 & 3200 \\
\hline & & $\begin{array}{l}\text { Chlamidiosis } \\
\text { (CBR) }\end{array}$ & 20 & 10 & 10 \\
\hline & \multirow{4}{*}{3} & PIV-3 (RIH) & 2560 & 1280 & 1280 \\
\hline & & IBR (EIA) & 3200 & 1600 & 3200 \\
\hline & & BVD (EIA) & 12800 & 6400 & 6400 \\
\hline & & $\begin{array}{l}\text { Chlamidiosis } \\
\text { (CBR) }\end{array}$ & 20 & 10 & 20 \\
\hline \multirow{8}{*}{ 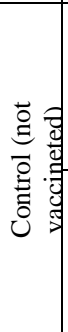 } & \multirow{4}{*}{4} & PIV-3 (RIH) & 10 & 5 & 40 \\
\hline & & IBR (EIA) & 200 & 100 & 200 \\
\hline & & BVD (EIA) & 100 & 200 & 400 \\
\hline & & $\begin{array}{l}\text { Chlamidiosis } \\
\text { (CBR) }\end{array}$ & 0 & 5 & 10 \\
\hline & \multirow{4}{*}{5} & PIV-3 (RIH) & 10 & 10 & 80 \\
\hline & & IBR (EIA) & 100 & 100 & 400 \\
\hline & & BVD (EIA) & 200 & 100 & 200 \\
\hline & & $\begin{array}{l}\text { Chlamidiosis } \\
\text { (CBR) }\end{array}$ & 5 & 5 & 20 \\
\hline
\end{tabular}

During the autopsy of the animals of the control group, we observed erosion and ulcers in the oral cavity, cyanosis of the mucous membranes of the nasal cavity, accumulation of serous exudate in the lumen of the trachea, bronchi and alveoli, compaction of the apical lobes, hyperplasia of the pharyngeal and mesenteric lymph nodes, and also hemorrhagic enteritis.

At the final stage the aim of the work was to test the developed vaccine in dysfunctional livestock farms in terms of respiratory and intestinal infections, as well as to determine the cost-effectiveness of preventive vaccination using this vaccine.

For three years the preventive treatment of cows and calves with experimental series of the associated vaccine was conducted. Only healthy animals were vaccinated, intramuscularly, twice with an interval of 14-20 days with the following doses: calves from 3 days to 6 months old $-1.0 \mathrm{~cm}^{3}$, young animals over the age of 6 months and adult animals $-2.0 \mathrm{~cm}^{3}$. Calves were revaccinated once 6 months later in a dose of $2.0 \mathrm{~cm}^{3}$. Pregnant cows and heifers were vaccinated 1.5 to 2 months before calving. Clinical observations carried out after vaccination did not reveal a local and general reaction to the preparation.

The analysis of the data showed that within three years of the use of the vaccine on the farm the incidence of calves decreased significantly and the percentage of their safety increased, which indicated the effectiveness of the tested vaccine. In addition, the number of calves increased by 1.5 times on the farm, their incidence and mortality decreased by 5 and 4.2 times, respectively. Besides, dairy herd increased by 1.3 times and the number of calves per 100 cows increased from 84 animals before the use of vaccine to 101 animals within three years after the use of the vaccine, which is 1.2 times more, and the safety of young animals reached $97,9 \%$.

The cost-effectiveness of the vaccine in the household was also calculated. We found out that after the start of using of the vaccine the total economic damage from the above diseases per 1 animal was decreasing annually by $30 \%, 60 \%$ and $75 \%$. Economical efficiency of vaccination per 1 ruble of costs during the first year was $4.7 \mathrm{rub}$., the $2^{\text {nd }}$ year $-9.0 \mathrm{rub}$ and the $3^{\text {rd }}$ year -10.7 rub. Average economical efficiency rate in 3 years was 8 rubles per 1 ruble of expenses.

\section{Conclusion}

The results of laboratory and production tests, as well as calculations of economic efficiency of the "Associated vaccine against parainfluenza-3, infectious bovine rhinotracheitis and chlamidiosis of livestock, inactivated emulsive» developed in FSBSI «FCTRB-VNIVI» showed that it has high antigenic activity and immunogenic properties, and can be recommended as a part of veterinary practice for specific prevention of viral respiratory infections of cattle.

\section{References}

1. K.P. Yurov, A.F. Shulyak, O.G. Petrova, O.V. Maiji, Trudi VIEV, 73, 22 (2003)

2. A.G. Glotov, T.I. Glotova, Respiratory diseases of the calves of the virus-bacterial etiology (Agros, 2008)

3. F.P. Petryankin, O.Yu. Petrova, Diseases of young animals (Lan, St. Petersburg, 2014)

4. V.A. Mishenko, V.V. Dumova, O.Yu. Chernih, Veter. Medic. of Kuban, 3, 13-15 (2011)

5. V.V. Evstifeev, V.G. Gumerov, M.N. Konnov, I.R. Akbashev, M.I. Klyatskiy, Sci. and Pract. J. Veter. Medic., Zootechn. and Biotechn., 1, 11-16 (2019) 
6. I.A. Bakulov, G.G. Yurkov, A.P. Peskovetsky, Recommendations on the methodology of epizootological examination (Pokrov, 1979)

7. Guidelines for the comprehensive clinical examination of cattle (Moscow, 1988)

8. I.R. Akbashev, Sci. notes of Kazan State Acad. of Veter. Medic., 2, 13-16 (2016)
9. Methodology for determining the economic efficiency of veterinary procedures, approved by the chief of the Veterinary Department of the Ministry of Agriculture of Russian Federation V.M. Avilov (Moscow, 1997) 